\title{
Effects of Magnetite Aggregate and Steel Powder on Thermal Conductivity and Porosity in Concrete for Nuclear Power Plant
}

\author{
Han-Seung Lee ${ }^{1}$ and Seung-Jun Kwon ${ }^{2}$ \\ ${ }^{1}$ Department of Architectural Engineering, Hanyang University, ERICA, Ansan 426-791, Republic of Korea \\ ${ }^{2}$ Department of Civil Engineering, Hannam University, Daejeon 306-791, Republic of Korea \\ Correspondence should be addressed to Seung-Jun Kwon; jjuni98@hannam.ac.kr
}

Received 11 August 2015; Revised 9 December 2015; Accepted 13 December 2015

Academic Editor: Wei Zhou

Copyright (c) 2016 H.-S. Lee and S.-J. Kwon. This is an open access article distributed under the Creative Commons Attribution License, which permits unrestricted use, distribution, and reproduction in any medium, provided the original work is properly cited.

\begin{abstract}
Among many engineering advantages in concrete, low thermal conductivity is an attractive property. Concrete has been widely used for nuclear vessels and plant facilities for its excellent radiation shielding. The heat isolation through low thermal conductivity is actually positive for nuclear power plant concrete; however the property may cause adverse effect when fires and melt-down occur in nuclear vessel since cooling down from outer surface is almost impossible due to very low thermal conductivity. If concrete containing atomic reactor has higher thermal conductivity, the explosion risk of conductive may be partially reduced. This paper presents high thermally conductive concrete development. For the work, magnetite with varying replacements of normal aggregates and steel powder of $1.5 \%$ of volume are considered, and the equivalent thermal conductivity is evaluated. Only when the replacement ratio goes up to $30 \%$, thermal conductivity increases rapidly to 2.5 times. Addition of steel powder is evaluated to be effective by 1.08 1.15 times. In order to evaluate the improvement of thermal conductivity, several models like ACI, DEMM, and MEM are studied, and their results are compared with test results. In the present work, the effects of steel powder and magnetite aggregate are studied not only for strength development but also for thermal behavior based on porosity.
\end{abstract}

\section{Introduction}

Concrete, as a construction material, has many engineering advantages and an effectiveness to corrosion control $[1,2]$. Several weaknesses like cracking caused by drying shrinkage and hydration heat have been reported and they can cause more rapid steel corrosion accelerated. For chloride attack, crack effect on enlarged diffusion has been studied $[3,4]$ and it has been also investigated for rapid carbonation behavior [5-7]. However concrete still has been widely used for its costbenefit and stable dimensional behavior. Nuclear containment and vessels need strong barrier against radioactivity so that concrete structure is mainly constructed for the use $[8,9]$. Another engineering merit is very low thermal conductivity compared with steel by $1 / 40 \sim 1 / 50[10,11]$, which can provide very stable conditions for nuclear reactor inside $[12,13]$. A few years ago, nuclear explosion at Fukushima in Japan happened and the disastrous effects are still in progress [14, 15]. When temperature of reactor is rapidly raised and cooling system inside is out, the huge concrete container acts as insulation vessel so that the explosion risk increases as well. In the disaster at Fukushima, cooling water is poured to the outer surface concrete but the effect is almost negligible since concrete intrinsically has low thermal conductivity. Even if concrete with high thermal conductivity has little effect on cooling down of reactor, the risk of additional explosion may be reduced.

This paper presents a concrete mix design for higher thermal conductivity adopting MA (magnetite aggregate) and SP (steel powder). Concrete is composite material containing gravel, sand, and air in pore. The individual thermal properties have already been studied $[16,17]$ and the mineral admixtures such as FA (Fly Ash) and GGBFS (Ground Granulated Blast Furnace Slag) are also investigated. ACI $122 \mathrm{R}$ provided a guideline for calculation of thermal conductivity using weight measurement of concrete; however the techniques are only for normal concrete [18]. 
In the present paper, MA and SP with high thermal conductivity are partially replaced with normal aggregates. Enlarging up to $42.3 \%$ of MA and $1.5 \%$ of SP for concrete volume, thermal conductivities of concrete are evaluated and the results are compared with those from several models like ACI 122R Model, DEMM (Differential Effective Medium Model), and MEM (Modified Eshelby Model) which can consider equivalent thermal conductivity in three-phase composites. The thermal behaviors and basic engineering properties of concrete are discussed in the work with varying volume rations of MA and SP.

\section{Analysis Technique for Thermal Conductivity}

\subsection{Background Theory}

2.1.1. Upper and Lower Level of Thermal Conductivity. The upper and lower equivalent thermal conductivity in layeredcomposite can be determined as the two conditions in Figure 1, whose theory can be applied to mass transport like water $[19,20]$.

The upper and lower conductivity can be obtained as (1) and (2), respectively, which are based on the assumptions like (1) without exothermic reaction, (2) constant thermal conduction, and (3) isolated from input/output of heat flow:

$$
\begin{aligned}
Q_{\mathrm{eq}} & =\frac{A}{\left(A_{1} / Q_{1}+A_{2} / Q_{2}+\cdots+A_{n} / Q_{n}\right)}=\frac{1}{\sum A_{f_{i}} Q_{i}}, \\
Q_{\mathrm{eq}} & =\frac{\left(A_{1} Q_{1}+A_{2} Q_{2}+\cdots+A_{n} Q_{n}\right)}{A}=\sum A_{f_{i}} Q_{i},
\end{aligned}
$$

where $Q_{\mathrm{eq}}$ is equivalent thermal conductivity and $Q_{i}$ is thermal conductivity in each material. $A_{i}$ and $A_{f_{i}}$ are each area and area fraction of each material, respectively. The above models cannot present the changes in thermal conductivity of concrete since concrete itself is not homogeneous with pores, aggregates, and cement hydrates.

2.1.2. Models for Equivalent Thermal Conduction of DEMM, $M E M$, and ACI 122R. The above theories in Section 2.1.1 have very limited application to thermal conduction in concrete since it contains pores and aggregates arbitrarily. The lower and upper limitation can be applied to thin plate and fiber composites. The pores and aggregates in concrete can be assumed as spherical shape which are irregularly scattered in concrete. The models of DEMM and MEM can handle equivalent thermal conductivity in composite with 3 phases.

(1) DEMM (Differential Effective Medium Model) [21-23]. The generalized DEMM with different components can be written as (3) with 1st differential equation form:

$$
\frac{d k_{c}}{d f}=\frac{k_{c}}{(1-f)} \sum_{i} f_{i} \frac{k_{c}-k_{f_{i}}}{\left(k_{c}-k_{f_{i}}\right) S-k_{c}},
$$

where $k_{c}, k_{f_{i}}, S, f$, and $f_{i}$ are equivalent thermal coefficient in composite, each thermal coefficient in spherical particle,

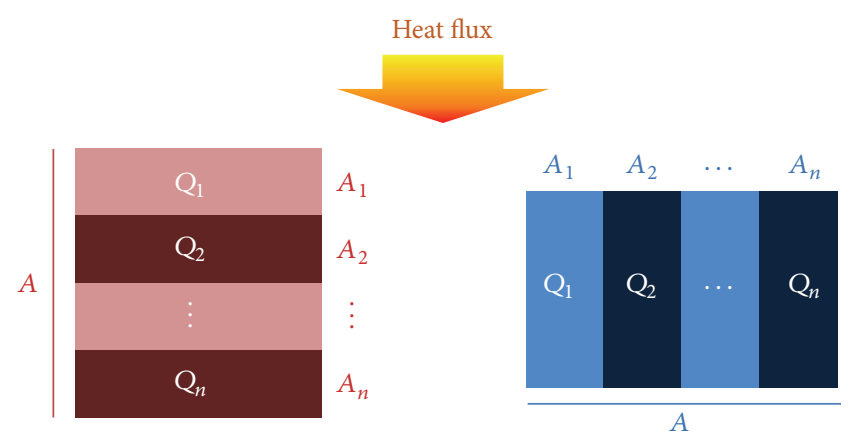

FIGURE 1: Critical boundaries of thermal conductivity in composite layers.

polarization coefficient, total volume ratio $(=1.0)$, and each volume ratio of component, respectively. In order to consider 3 components, one component is firstly calculated and the result is reconsidered as original medium. The thermal conductivity in reconsidered medium $\left(k_{m 1}\right)$ can be written as

$$
\begin{gathered}
\left(\frac{k_{m 1}}{k_{m}}\right)^{3}-3\left(\frac{k_{f_{1}}}{k_{m}}\right)\left(\frac{k_{m 1}}{k_{m}}\right)^{2}+3\left(\frac{k_{f_{1}}}{k_{m}}\right)^{2}\left(\frac{k_{m 1}}{k_{m}}\right) \\
+\left(1-f_{1}^{\prime}\right)^{3}\left(\frac{k_{f_{1}}}{k_{m}}-1\right)^{3} \frac{k_{m 1}}{k_{m}}-\left(\frac{k_{f_{1}}}{k_{m}}\right)^{3}=0,
\end{gathered}
$$

where $k_{m}$ is thermal conductivity in original medium and $k^{\prime}$ is obtained as

$$
f_{1}^{\prime}=\frac{f_{1}}{\left(1-f_{2}\right)} .
$$

The final equivalent thermal conductivity $\left(k_{c}\right)$ can be obtained through recalculating $k_{m 1}$ as

$$
\begin{gathered}
\left(\frac{k_{c}}{k_{m 1}}\right)^{3}-3\left(\frac{k_{f_{2}}}{k_{m 1}}\right)\left(\frac{k_{c}}{k_{m 1}}\right)^{2}+3\left(\frac{k_{f_{2}}}{k_{m 1}}\right)^{2}\left(\frac{k_{c}}{k_{m 1}}\right) \\
+\left(1-f_{2}\right)^{3}\left(\frac{k_{f_{2}}}{k_{m 1}}-1\right)^{3} \frac{k_{c}}{k_{m 1}}-\left(\frac{k_{f_{2}}}{k_{m 1}}\right)^{3}=0 .
\end{gathered}
$$

The derived equivalent thermal conductivity is compared with the results of test, MEM, and ACI 122R.

(2) MEM (Modified Eshelby Model) [22-24]. In the MEM, 2 spherical components with different thermal conductivity are irregularly arranged in concrete with constant thermal conductivity and it is subject to constant thermal velocity of $q^{0}$ ( $x_{3}$ direction). The MEM is shown in Figure 2 [22].

In Figure 2, constant thermal velocity $\left(q^{0}\right)$ can be written as (7) in which $K_{m}$ and $Z^{0}$ are equivalent thermal conductivity matrix and constant thermal gradient without components. When the fluctuating temperature in the composite is integrated, the result is zero so that the condition of (8) can be assumed $[22,23]$ :

$$
\begin{aligned}
q^{0} & =-K_{m} Z^{0}, \\
\bar{Z}+f_{1}\left(Z^{1}-Z^{* 1}\right)+f_{2}\left(Z^{2}-Z^{* 2}\right) & =0,
\end{aligned}
$$



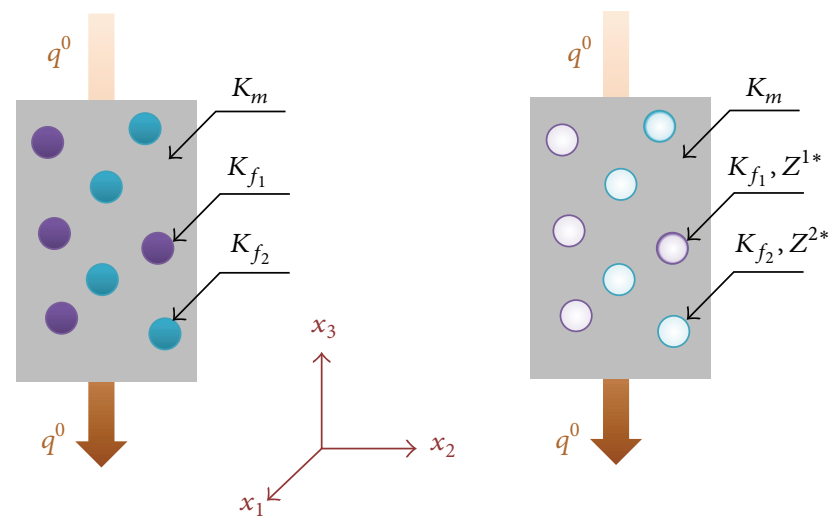

FIGURE 2: MEM for equivalent thermal conductivity in composite.

where $Z^{i}$ and $Z^{i *}$ are disturbed temperature gradient and intrinsic temperature gradient from Eshelby model in $i$ component. $\bar{Z}$ is average of disturbed temperature gradient.

The intrinsic temperature gradient can be obtained as (9a) and (9b) through matrix transformation:

$$
\begin{aligned}
Z^{* 1} & =\left(A_{11}-A_{12} A_{22}^{-1} A_{21}\right)^{-1}\left(D_{1}-A_{12} A_{22}^{-1} D_{2}\right) q^{0} \\
& =F_{1} q^{0}, \\
Z^{* 2} & =\left(A_{22}-A_{21} A_{11}^{-1} A_{12}\right)^{-1}\left(D_{2}-A_{21} A_{11}^{-1} D_{1}\right) q^{0} \\
& =F_{2} q^{0} .
\end{aligned}
$$

Then component of $A_{i j}$ and $D_{i}$ can be written as the following equations [22]:

$$
\begin{aligned}
& A_{11}=\left\{\left(K_{f}^{1}-K_{m}\right)\left[\left(1-f_{1}\right) S^{1}+f_{1} I\right]+K_{m}\right\}, \\
& A_{12}=f_{2}\left(K_{m}-K_{f}^{1}\right)\left(S^{2}-I\right), \\
& D_{1}=\left(K_{m}-K_{f}^{1}\right) K_{m}^{-1}, \\
& A_{21}=f_{1}\left(K_{m}-K_{f}^{2}\right)\left(S^{1}-I\right), \\
& A_{22}=\left\{\left(K_{f}^{2}-K_{m}\right)\left[\left(1-f_{2}\right) S^{2}+f_{2} I\right]+K_{m}\right\}, \\
& D_{2}=\left(K_{m}-K_{f}^{2}\right) K_{m}^{-1} .
\end{aligned}
$$

The equivalent temperature gradient $\left(Z_{c}\right)$ is written as (11) with temperature gradient of base media $\left(Z_{m}\right)$ and each component $\left(Z_{f}^{i}\right)$ :

$$
Z_{c}=(1-f) Z_{m}+f_{1} Z_{f}^{1}+f_{2} Z_{f}^{2} .
$$

Thermal velocity $\left(q^{0}\right)$ should be the same as the equivalent thermal conductivity matrix multiplied by equivalent temperature gradient, which leads to

$$
q^{0}=-K_{c} Z_{c}=q_{c} .
$$

Considering the previous equations of (8) (12), the equivalent conductivity matrix $\left(K_{c}\right)$ is derived as (13). Since the matrix of $K_{c}, F_{1}$, and $F_{2}$ is diagonal matrix, the equivalent thermal conductivity with 3 different phases is derived as (14). Consider

$$
\begin{aligned}
K_{c} & =\left(K_{m}+f_{1} F_{1}+f_{2} F_{2}\right)^{-1}, \\
\frac{k_{c}}{k_{m}} & =1+3\left[\frac{1}{1-\left(\left(k_{f_{1}}-k_{m}\right) /\left(k_{f_{1}}+2 k_{m}\right)\right) f_{1}-\left(\left(k_{f_{2}}-k_{m}\right) /\left(k_{f_{2}}+2 k_{m}\right)\right) f_{2}}-1\right] .
\end{aligned}
$$

(3) ACI 221R [18]. In the guide of ACI 221R, simple method is proposed for thermal conductivity measurement like (15a) and (15b) as follows:

$$
\begin{array}{ll}
k_{c}=0.0720 e^{0.00125 d}, & \text { Oven dried, } \\
k_{c}=0.0865 e^{0.00125 d}, & \text { Air dried, }
\end{array}
$$

where $k_{c}$ and $d$ are thermal conductivity $(\mathrm{W} / \mathrm{m} \cdot \mathrm{K})$ and weight $\left(\mathrm{kg} / \mathrm{m}^{3}\right)$ in concrete.

\section{Experimental Program for High Thermal Conductive Concrete with MA and SP}

3.1. Mix Proportions. The previous mix proportions for nuclear power plant concrete are utilized, containing $20 \%$ replacement ratio of FA (Fly Ash) and W/C ratio of 0.4 [12]. The mix proportions for the study are listed in Table 1.

In Table 1, M50M25S denotes 50\% replacement ratio of MA for gravel, 25\% replacement ratio of MA for sand, and addition of SP with $1.5 \%$ of total volume. The chemical compositions of OPC and FA are listed in Table 2. The physical properties of aggregates are presented in Table 3 and the physical properties of SP are also presented in Table 4 . The photos of SP and MA are shown in Figure 3.

3.2. Thermal Conductivity Test. The samples with 9 cases are prepared and the test is performed referring to KS L ISO 8302 method [25]. The samples have the geometry with $100 \times 100$ $\times 50 \mathrm{~mm}$. The test equipment and the samples are shown in Figure 4 . 
TABLE 1: Mix proportions for concrete test.

\begin{tabular}{|c|c|c|c|c|c|c|c|c|c|c|}
\hline \multirow{2}{*}{ Type } & \multicolumn{9}{|c|}{ Unit content $\left(\mathrm{kg} / \mathrm{m}^{3}\right)$} & \multirow{2}{*}{$R(\%)$} \\
\hline & $\mathrm{W}$ & $\mathrm{C}$ & FA & G & S & WRA & MG & MS & SP & \\
\hline Control & 163 & 324 & 82 & 935 & 750 & 2 & 0 & 0 & 0 & 0 \\
\hline M50M25 & 210 & 420 & 105 & 468 & 563 & 2 & 468 & 188 & 0 & 22.9 \\
\hline M50M25S & 210 & 420 & 105 & 468 & 563 & 2 & 468 & 188 & 120 & 22.9 \\
\hline M50M50 & 216 & 432 & 108 & 468 & 375 & 2 & 468 & 375 & 0 & 29.3 \\
\hline M50M25S & 216 & 432 & 108 & 468 & 375 & 2 & 468 & 375 & 120 & 29.3 \\
\hline M90M25 & 220 & 440 & 110 & 104 & 563 & 2 & 831 & 188 & 0 & 35.9 \\
\hline M90M25S & 220 & 440 & 110 & 104 & 563 & 2 & 831 & 188 & 120 & 35.9 \\
\hline M90M50 & 230 & 460 & 115 & 104 & 375 & 2 & 831 & 375 & 0 & 42.3 \\
\hline M90M50S & 230 & 460 & 115 & 104 & 375 & 2 & 831 & 375 & 120 & 42.3 \\
\hline
\end{tabular}

W: water, C: cement, FA: Fly Ash, G: gravel, S: sand, WRA: water reducing agent, MG: magnetite gravel, MS: magnetite sand, SP: steel powder, and R: replacement ratio of volume.

TABLE 2: Chemical compositions of binder (OPC and FA).

\begin{tabular}{lccccccccc}
\hline Type & $\mathrm{SiO}_{2}$ & $\mathrm{Fe}_{2} \mathrm{O}_{3}$ & $\mathrm{CaO}$ & $\mathrm{MgO}$ & $\mathrm{SO}_{3}$ & $\mathrm{Al}_{2} \mathrm{O}_{3}$ & $\mathrm{TiO}_{2}$ & The others & Ig.loss \\
\hline OPC & 21.95 & 2.81 & 60.12 & 3.32 & 2.11 & 6.59 & - & 3.1 & 1.85 \\
\hline FA & 53.60 & 9.40 & 4.70 & 2.60 & 1.80 & 20.00 & 4.2 & 3.8 \\
\hline
\end{tabular}

TABLE 3: Physical properties of aggregate.

\begin{tabular}{lcccc}
\hline Types & $\begin{array}{c}G_{\max } \\
(\mathrm{mm})\end{array}$ & $\begin{array}{c}\text { Density } \\
\left(\mathrm{kg} / \mathrm{m}^{3}\right)\end{array}$ & $\begin{array}{c}\text { Absorption } \\
\text { ratio (\%) }\end{array}$ & $\begin{array}{c}\text { Fineness } \\
\text { modulus }\end{array}$ \\
\hline Sand & & & & \\
$\quad$ Normal & 5 & 2,550 & 2.20 & 2.40 \\
$\quad \begin{array}{l}\text { Magnetite } \\
\text { Coarse aggregate }\end{array}$ & 5 & 4,200 & - & 2.21 \\
$\quad$ Normal & 19 & 2,500 & 0.80 & 7.10 \\
$\quad$ Magnetite & 19 & 4,180 & - & 6.80 \\
\hline
\end{tabular}

\section{Evaluation of Strength, Weight, and Thermal Conductivity}

4.1. Test Results of Compressive Strength, Weight, and Thermal Conductivity. Compressive strength is measured after submerged curing for 28 days, referring to KS F 2403. The samples show compressive strength higher than $40 \mathrm{MPa}$ and the effect of MA and SP on strength development is not significant. The test results of compressive strength with weight are shown in Figure 5 considering replacement ratio of MA. The weight increases to $127 \%$ when replacement of volume reaches $42.3 \%$ (M90M50S).

The strength shows slight reduction when MA replacement ratio goes up to $40 \%$ with SP addition. The reasons are different fineness modulus of MA from normal aggregate and absorbed WRA around SP with carbon [26, 27].

The previous studies report that thermal conductivities of SP and MA are in the range of $46.5 \sim 58.2(\mathrm{~W} / \mathrm{m} \cdot \mathrm{K})$ and $6 \sim 23(\mathrm{~W} / \mathrm{m} \cdot \mathrm{K})$, respectively [28]. The values vary with moisture content. The thermal conductivities in normal concrete components are summarized in Table 5 [29].

The test results of thermal conductivity are shown in Figure 6, which shows increment by $2.54 \sim 2.74$ times in the case of maximum replacement $(42.3 \%$ volume of replacement). Up to $22.9 \%$ of replacement ratio, the effect of replacement of MA on thermal conductivity seems to be small but from $29.3 \%$ the values of thermal conductivity rapidly increase to $3.441 \mathrm{~W} / \mathrm{m} \cdot \mathrm{K}$. The effect of SP shows reasonable increase in thermal conductivity with increasing MA replacement as shown in Figure 7.

4.2. Comparison of Test Results with Previous Models. In the chapter, models of DEMM, MEM, and ACI explained in Section 2.1.2 are attempted for comparison with test results. The variables of MA and SP are assumed based on the previous research $[29,30]$. Table 6 lists the analysis conditions for equivalent thermal conductivity in composite with 3 phases.

Actually the tested concrete has several components containing different thermal conductivities such as air content, cement hydrates, coarse aggregate, sand, and FA. However, MA and SP have relatively higher thermal conductivity than the components in normal concrete, so that 3 phases are determined as normal concrete, MA, and SP for thermal conductivity evaluation. In the case without SP, two-phase analysis is conducted. The comparisons with test and equivalent models are shown in Figure 8 including ACI model.

As shown in Figure 8, the results from DEMM, MEM, and ACI models are reasonably in agreement with those from test over $30 \%$ replacement of MA, which shows about $2 / 3$ level of upper limit.

The reasons for the relatively big errors can be explained in several ways. The sample was prepared with $100 \times 100 \times$ $50 \mathrm{~mm}$ and has thickness of $50 \mathrm{~mm}$ with 1 hour of test period. If thickness decreases below $50 \mathrm{~mm}$, prompt increase can be expected; however concrete has $19 \mathrm{~mm}$ of coarse aggregated size. If normal aggregate and pores are concentrated in the particular area, concrete cannot reflect the effect of magnetite 
TABLE 4: Physical properties of SP.

\begin{tabular}{lcccc}
\hline Density $\left(\mathrm{g} / \mathrm{cm}^{3}\right)$ & Purity $(\%)$ & Melting point $\left({ }^{\circ} \mathrm{C}\right)$ & Particle size $(\mathrm{mm})$ & Carbon content $(\%)$ \\
\hline 7.87 & over 98.0 & 932 & $<5 \mathrm{~mm}$ & $<1.5 \%$ \\
\hline
\end{tabular}

TABLE 5: Thermal conductivity in normal concrete component (in room condition).

\begin{tabular}{lccc}
\hline Types & OPC mortar & FA mortar & Normal aggregate \\
\hline Thermal conductivity $(\mathrm{W} / \mathrm{m} \cdot \mathrm{K})$ & 1.2 & 0.9 & $1.3 \sim 2.8$ \\
\hline
\end{tabular}

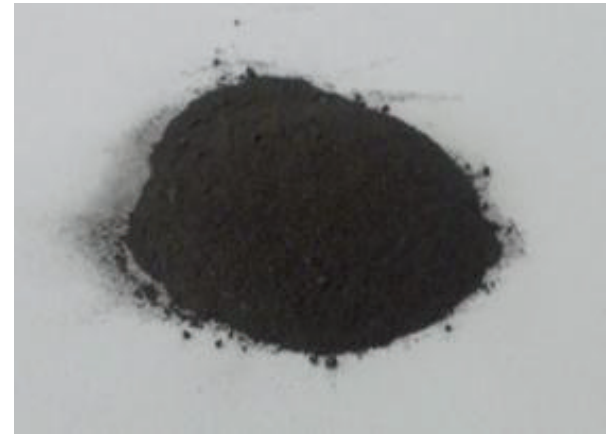

(a) Steel powder

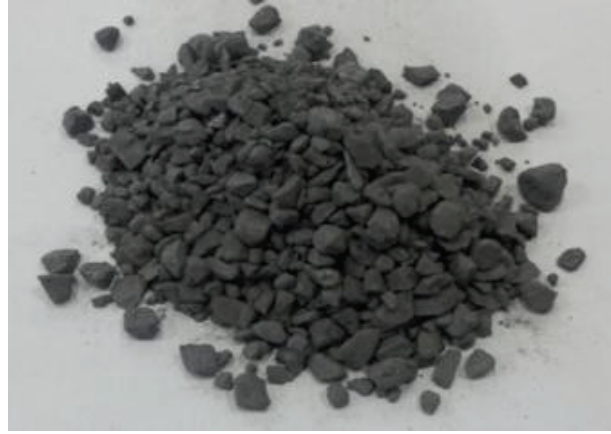

(b) Magnetite aggregate

FIgURE 3: Photos of SP and MA.

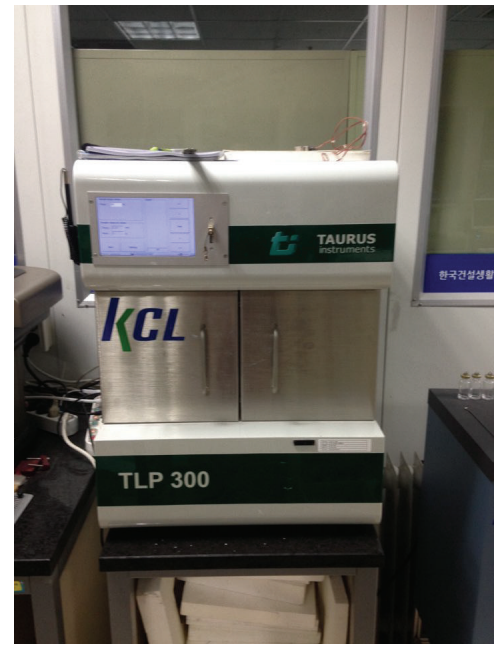

(a) Test equipment

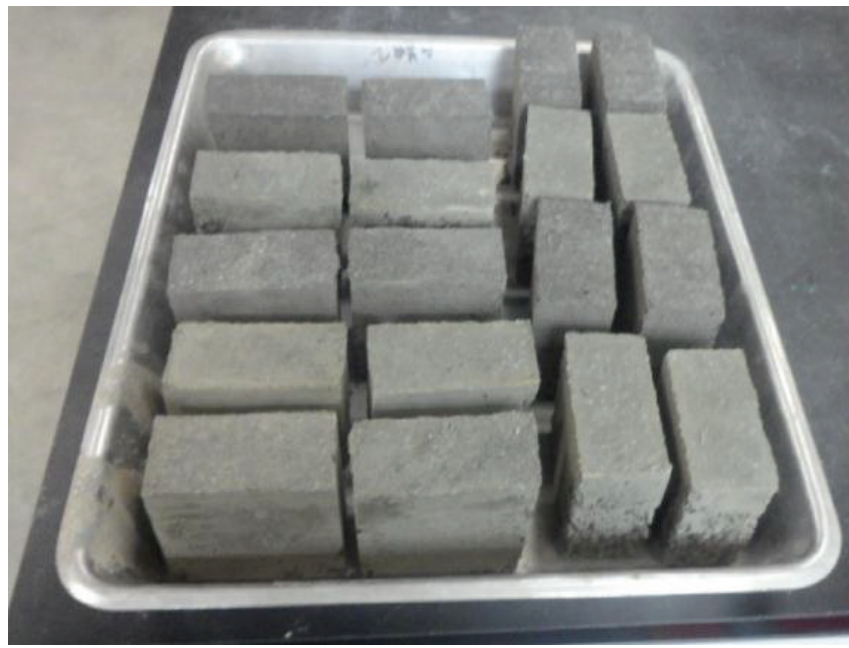

(b) Test samples

FIGURE 4: Photos of thermal conductivity measurement and samples.

TABLE 6: Analysis condition for equivalent thermal conduction.

\begin{tabular}{lcc}
\hline Material & Density $\left(\mathrm{kg} / \mathrm{m}^{3}\right)$ & Thermal conductivity $(\mathrm{W} / \mathrm{m} \cdot \mathrm{K})$ \\
\hline Magnetite & 4,200 & 10 \\
Steel powder & 7,800 & 45 \\
\hline
\end{tabular}

and steel powder. After replacing 30\% volume ratio with magnetite, thermal conductivity reasonably meets with the previous numerical techniques and ACI recommendation as shown in Figure 8.
4.3. Porosity and Thermal Conductivity. The thermal conductivity in concrete is much lower than that in SP and MA so that concrete as media is assumed as containing constant thermal conductivity in Section 4.2. However the conductivities of air, cement hydrates, and normal aggregate are all different. The larger pores it has, the lower thermal conductivity it also has, since conductivity of air is much lower than that of concrete by about 70 times [10, 11]. The measured porosities through MIP are shown in Figure 9 and the reduced porosity is consistent with the increased thermal 


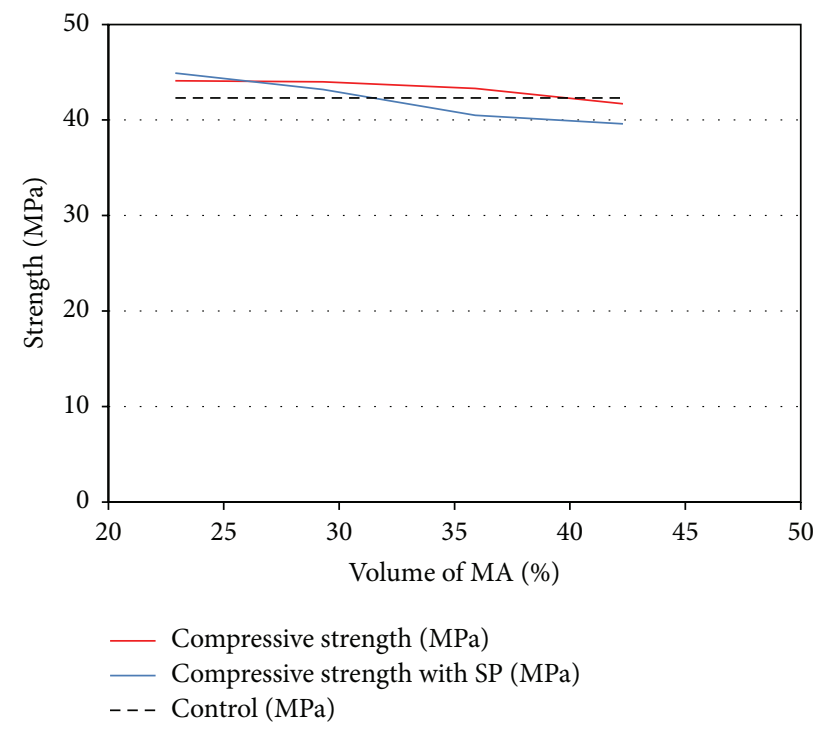

(a) Volume and strength

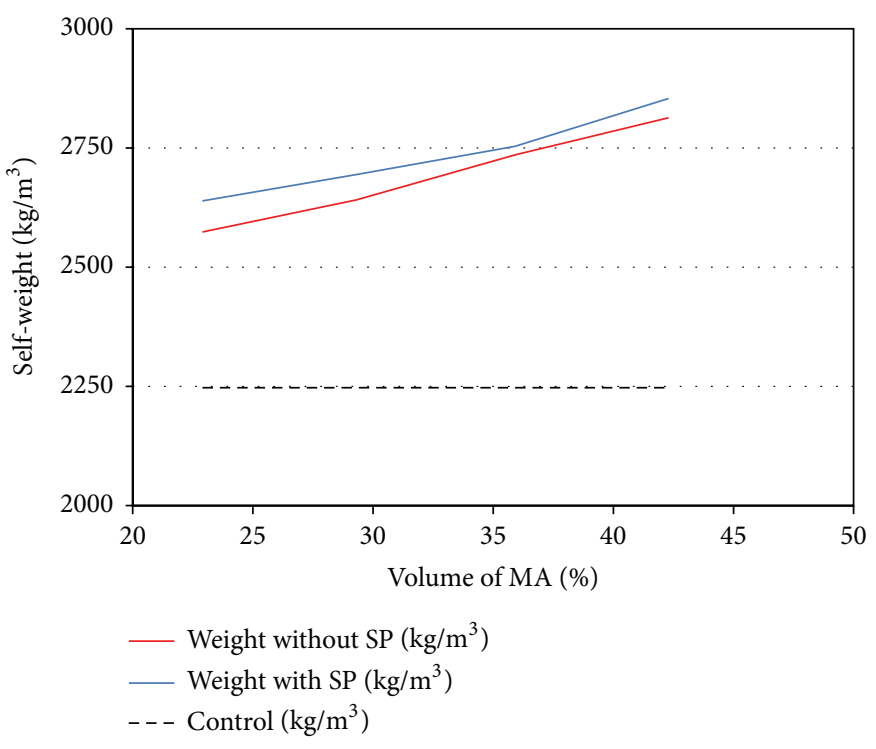

(b) Volume and self-weight

FIGURE 5: Changes in physical performance with varying MA replacement ratios.

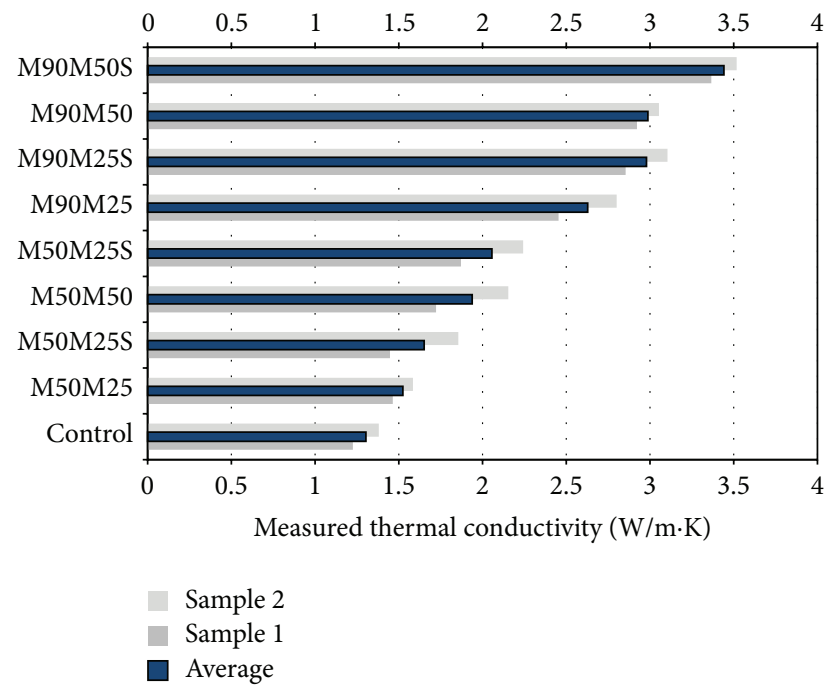

FIGURE 6: Measured thermal conductivity varying replacement ratios.

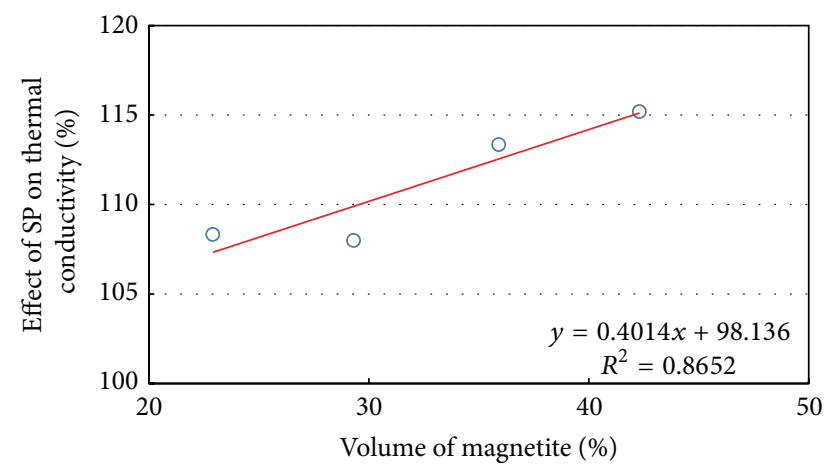

Figure 7: SP effect on thermal conductivity. conductivity. The measured thermal conductivity and the reduced porosity are also shown in Figure 10.

The addition of SP (2 4\% of volume) is reported to cause the reduced porosity and enhancement of chloride resistance [31, 32]. The used MA has more small particles, which leads to pore compaction. Pores and its connectivity play an important role in thermal conductivity and heat transfer. The relatively higher porosity before replacing MA has lower thermal conductivity and it rapidly increases with reduced porosity and addition of MA and SP with much higher thermal conductivity.

In the paper, concrete mix technique which can increase thermal conductivity is attempted through replacing magnetite aggregate and adding steel powder, and the results are compared with several models aiming at equivalent conductivity with 3 different phases. With consideration of each component's characteristics, these models can provide more reasonable results. In the mix proportions for concrete with high thermal conductivity, fundamental performances such as strength and workability should be satisfied. More replacement of MA and addition of SP can increase the self-weight and thermal conductivity in nuclear power plant concrete; however its performances should be considered in advance.

\section{Conclusions}

(1) Replacing normal aggregates with magnetite aggregates ( $42.3 \%$ of volume) and adding steel powder (1.5\% of volume), thermal conductivity increases to 2.54 2.74 times to control mixture. Several models like DEMM, MEM, and ACI show reasonable agreement with test results and the overall test results are in the range of $2 / 3$ of upper limit. 

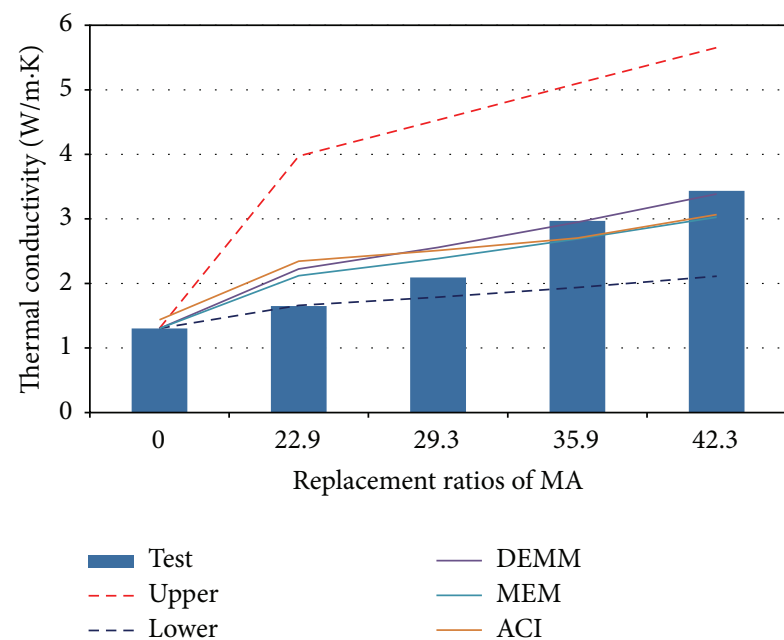

(a) Thermal conductivity without $\mathrm{SP}$

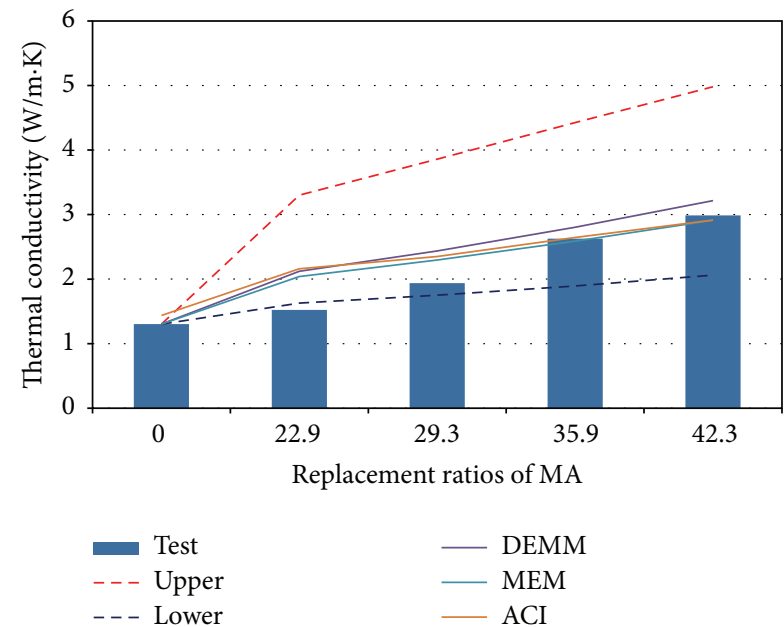

(b) Thermal conductivity with SP

FIGURE 8: Thermal conductivity of test and several models.

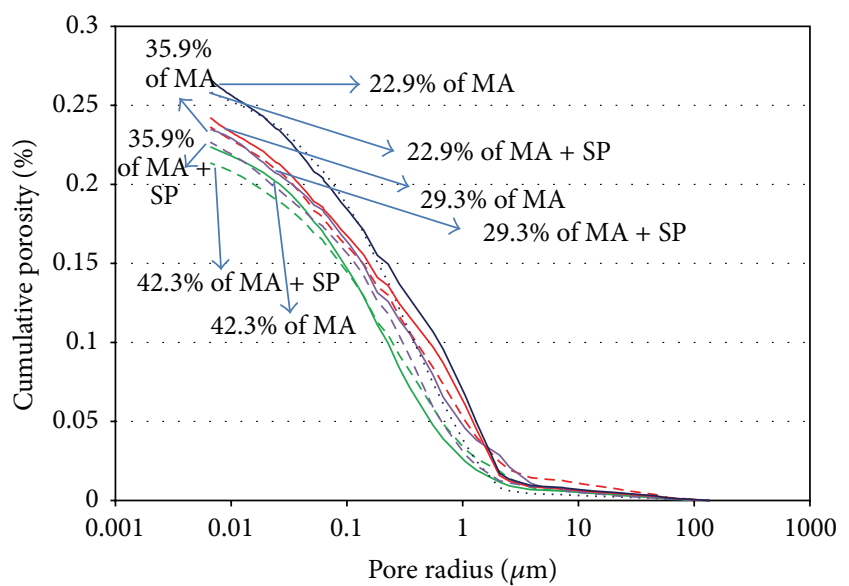

FIGURE 9: Reduced porosity with increasing MA and SP.

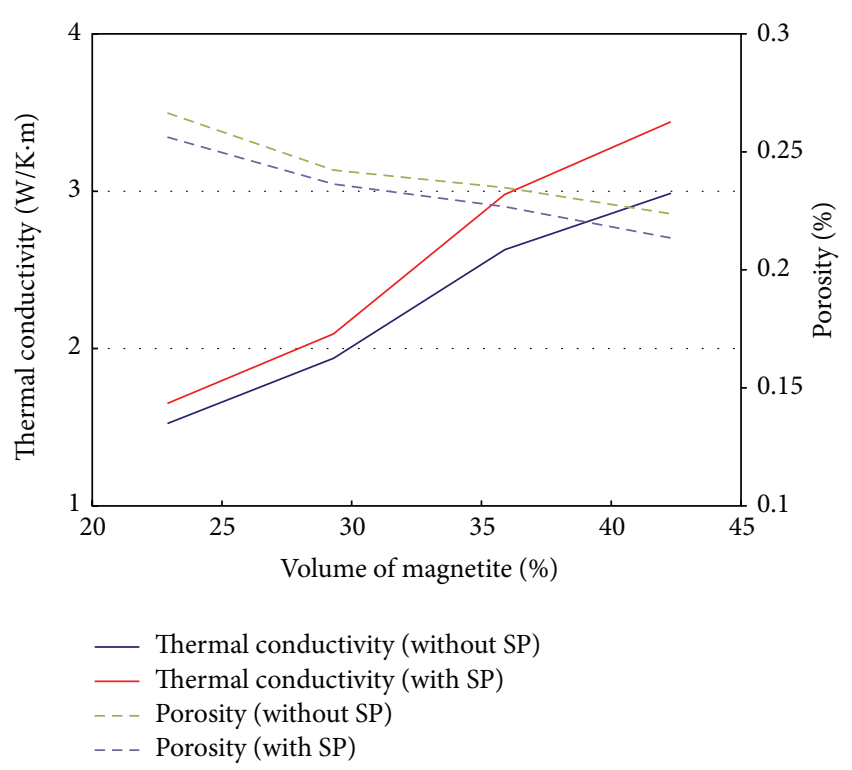

FIgURE 10: Thermal conductivity and reduced porosity.
(2) The replacement of MA is evaluated to be effective when it is up to $30 \%$. Steel powder is also effective, which shows 106 113\% increment of thermal conductivity with increasing MA replacement ratio. The reduced porosity due to $\mathrm{SP}$ and $\mathrm{MA}$ is also effective for increasing thermal conductivity.

(3) The low increasing thermal conductivity below $30 \%$ of magnetite replacement is caused by heterogeneous property in concrete since it randomly has pores, hydrates, and aggregates in the test sample thickness. The late response of thermal conductivity is also affected by relatively high thickness with big size of aggregate.

\section{Conflict of Interests}

The authors declare that there is no conflict of interests regarding the publication of this paper.

\section{Acknowledgments}

This research was supported by Basic Science Research Program through the National Research Foundation of Korea (NRF) funded by the Ministry of Science, ICT \& Future Planning (no. 2015R1A5A1037548) and also supported by the Ministry of Education (NRF-2013R1A1A2060114).

\section{References}

[1] J. P. Broomfield, Corrosion of Steel in Concrete: Understanding, Investigation and Repair, E\&FN, London, UK, 1997.

[2] M. D. A. Thomas and P. B. Bamforth, "Modeling chloride diffusion in concrete: effect of fly ash and slag," Cement and Concrete Research, vol. 29, no. 4, pp. 487-495, 1999.

[3] B. Gérard and J. Marchand, "Influence of cracking on the diffusion properties of cement-based materials. Part I. Influence of continuous cracks on the steady-state regime," Cement and Concrete Research, vol. 30, no. 1, pp. 37-43, 2000. 
[4] Q.-F. Liu, J. Yang, J. Xia, D. Easterbrook, L.-Y. Li, and X.Y. Lu, "A numerical study on chloride migration in cracked concrete using multi-component ionic transport models," Computational Materials Science, vol. 99, no. 3, pp. 396-416, 2015.

[5] H. Ranaivomananaa, J. Verdiera, A. Selliera, and X. Bourbonb, "Sealing process induced by carbonation of localized cracks in cementitious materials," Cement and Concrete Composites, vol. 37, no. 3, pp. 37-46, 2013.

[6] H.-W. Song, S.-J. Kwon, K.-J. Byun, and C.-K. Park, "Predicting carbonation in early-aged cracked concrete," Cement and Concrete Research, vol. 36, no. 5, pp. 979-989, 2006.

[7] S.-J. Kwon and U. J. Na, "Prediction of durability for RC column with crack and joint under carbonation based on probabilistic approach," International Journal of Concrete Structures and Materials, vol. 5, no. 1, pp. 11-18, 2011.

[8] Y. S. Choi and E. I. Yang, "Effect of calcium leaching on the pore structure, strength, and chloride penetration resistance in concrete specimens," Nuclear Engineering and Design, vol. 259, pp. 126-136, 2013.

[9] K. G. Field, I. Remec, and Y. L. Pape, "Radiation effects in concrete for nuclear power plants-part I: quantification of radiation exposure and radiation effects," Nuclear Engineering and Design, vol. 282, no. 2, pp. 126-143, 2015.

[10] J. W. M. Spicer, R. Osiander, L. C. Aamodt, and R. B. Givens, "Microwave thermoreflectometry for detection of rebar corrosion," in Structural Materials Technology III: An NDT Conference, vol. 3400 of Proceedings of SPIE, pp. 402-409, San Antonio, Tex, USA, 1998.

[11] P. Meshgin and Y. Xi, "Multi-scale composite models for the effective thermal conductivity of PCM-concrete," Construction and Building Materials, vol. 48, pp. 371-378, 2013.

[12] K. H. Yang and J. H. Moon, "Mix proportions and physical properties of heavy weight concrete for nuclear power plant," Korea Institute of Building and Construction, vol. 12, no. 3, pp. 9-14, 2012 (Korean).

[13] ACI Committee, "Code requirements for nuclear safety-related concrete structures," ACI 349-06, American Concrete Institute, 2006.

[14] O. Evrard, J. P. Laceby, H. Lepage, Y. Onda, O. Cerdan, and S. Ayrault, "Radiocesium transfer from hillslopes to the Pacific Ocean after the Fukushima Nuclear Power Plant accident: a review," Journal of Environmental Radioactivity, vol. 148, no. 10, pp. 92-110, 2015.

[15] K. Rehdanza, H. Welschc, D. Naritaa, and T. Okuboe, "Wellbeing effects of a major natural disaster: the case of Fukushima," Journal of Economic Behavior \& Organization, vol. 116, no. 8, pp. 500-517, 2015.

[16] S. E. Jeon, An experimental research on thermal properties of concrete [M.S. thesis], Department of Civil Engineering, Korea Advanced Institute of Science and Technology, 1997.

[17] K.-H. Kim, S.-E. Jeon, J.-K. Kim, and S. Yang, "An experimental study on thermal conductivity of concrete," Cement and Concrete Research, vol. 33, no. 3, pp. 363-371, 2003.

[18] ACI Committee, "Guide to thermal properties of concrete and masonry systems," ACI Committee 122R, American Concrete Institute, 2002.

[19] B. Mutnuri, Thermal conductivity characterization of composite materials [M.S. thesis], College of Engineering and Mineral Resources, West Virginia University, 2006.

[20] W. J. Parker, R. J. Jenkins, C. P. Butler, and G. L. Abbott, "Flash method of determining thermal diffusivity, heat capacity, and thermal conductivity," Journal of Applied Physics, vol. 32, no. 9, pp. 1679-1684, 1961.

[21] J. M. Molina, J. Narciso, L. Weber, A. Mortensen, and E. Louis, "Thermal conductivity of Al-SiC composites with monomodal and bimodal particle size distribution," Materials Science and Engineering A, vol. 480, no. 1-2, pp. 483-488, 2008.

[22] J. K. Lee and J. G. Kim, "Analytical study on effective thermal conductivity of three-phase composites," Journal of the Korea Academia-Industrial cooperation Society, vol. 12, no. 7, pp. 29312938, 2011 (Korean).

[23] A. N. Norris, A. J. Callegari, and P. Sheng, "A generalized differential effective medium theory," Journal of the Mechanics and Physics of Solids, vol. 33, no. 6, pp. 525-543, 1985.

[24] H. Hiroshi and T. Minoru, "Equivalent inclusion method for steady state heat conduction in composites," International Journal of Engineering Science, vol. 24, no. 7, pp. 1159-1172, 1986.

[25] Korean Standards, "Thermal insulation-determination of steady-state thermal resistance and related properties-guarded hot plate apparatus," KS L ISO 8302, 2006.

[26] P. K. Metha and P. J. M. Monteiro, Concrete: Structure, Properties, and Materials, vol. 2, Prentice Hall, Upper Saddle River, NJ, USA, 1993.

[27] S. H. Jung and S.-J. Kwon, "Engineering properties of cement mortar with pond ash in South Korea as construction materials: from waste to concrete," Central European Journal of Engineering, vol. 3, no. 3, pp. 522-533, 2013.

[28] M. P. Manahan, "Thermal expansion and conductivity of magnetite flakes taken from the Oconee- 2 steam generator," Journal of Materials Science, vol. 25, no. 8, pp. 3424-3428, 1998.

[29] A. Lanciani, P. Morabito, P. Rossi et al., "Measurements of the thermophysical properties of structural materials in laboratory and in situ: methods and instrumentation," High Temperatures-High Pressures, vol. 21, no. 4, pp. 391-400, 1989.

[30] J. M. Molina, R. Prieto, J. Narciso, and E. Louis, "The effect of porosity on the thermal conductivity of Al-12 wt.\% Si/SiC composites," Scripta Materialia, vol. 60, no. 7, pp. 582-585, 2009.

[31] J. J. Kim, M. C. Han, and G. G. Han, "Fundamental research on corrosion control for reinforcing bar by incorporation of steel powder," Conference of AIL-RA, vol. 1, no. 1, pp. 792-795, 2007.

[32] Y. Li, F. Kong, and R. Du, "Application of high performance concrete mixed with steel slag powder in concrete pavements," in Proceedings of the ASCE Critical Issues in Transportation System Planning, Development, and Management (ICCTP '09), vol. 1, pp. 1-7, 2009. 

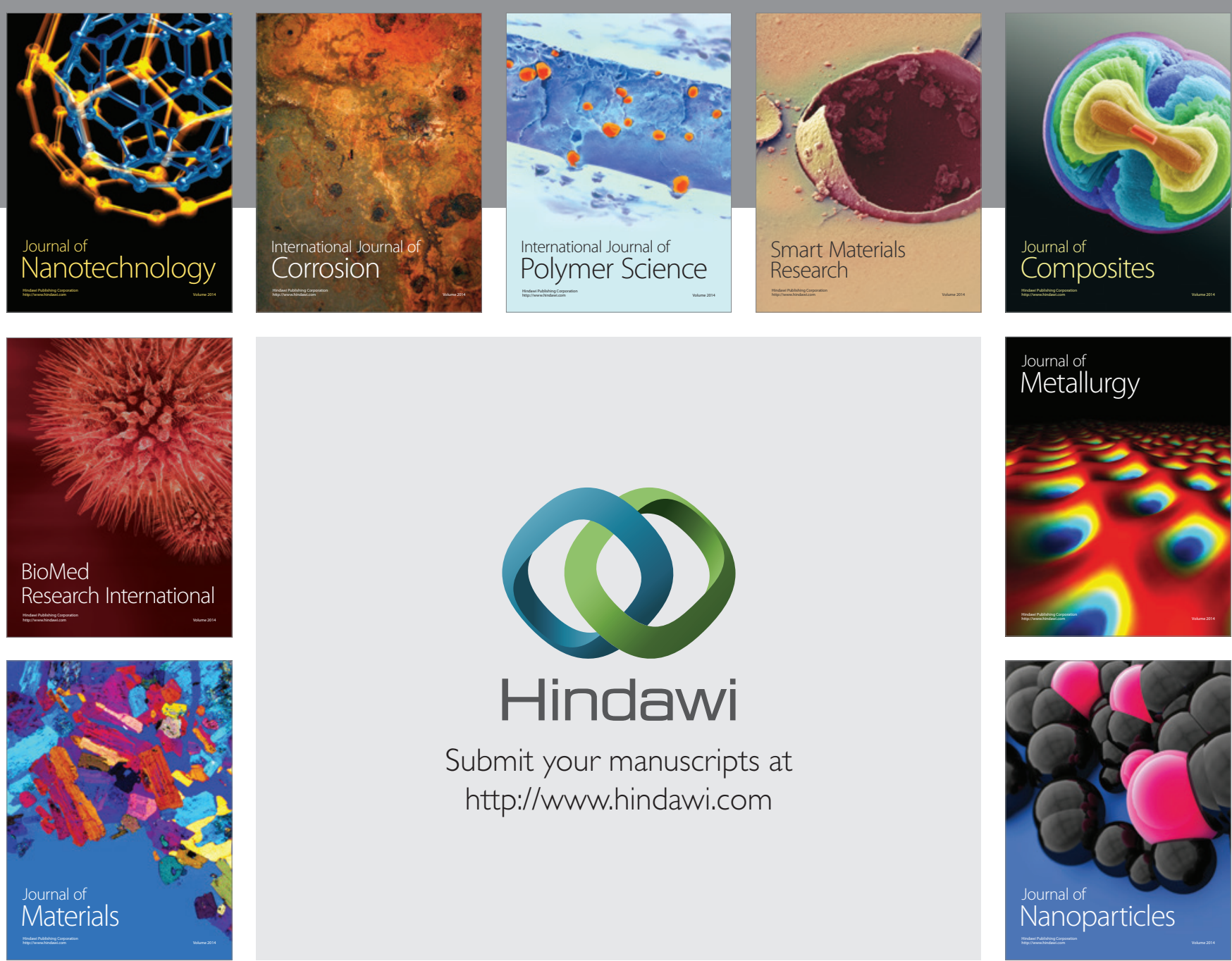

\section{Hindawi}

Submit your manuscripts at

http://www.hindawi.com

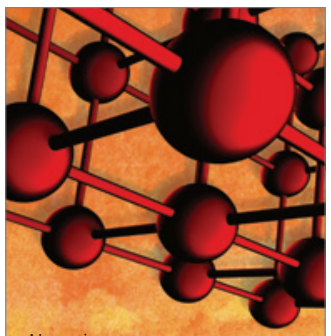

Materials Science and Engineering
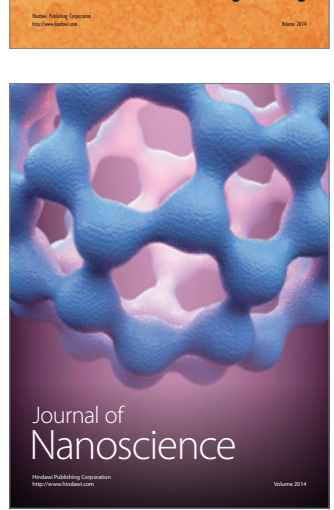
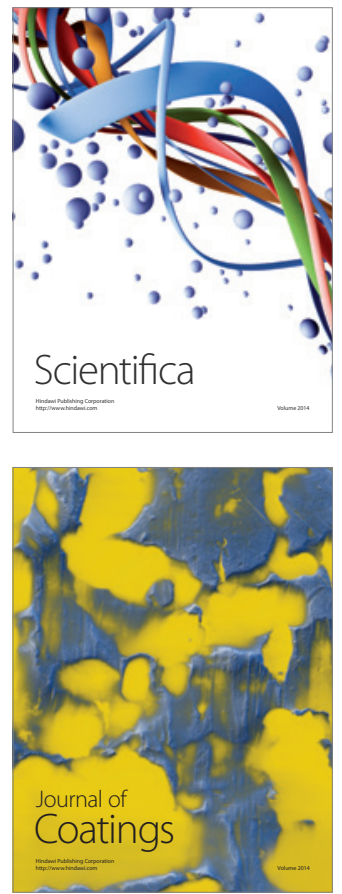
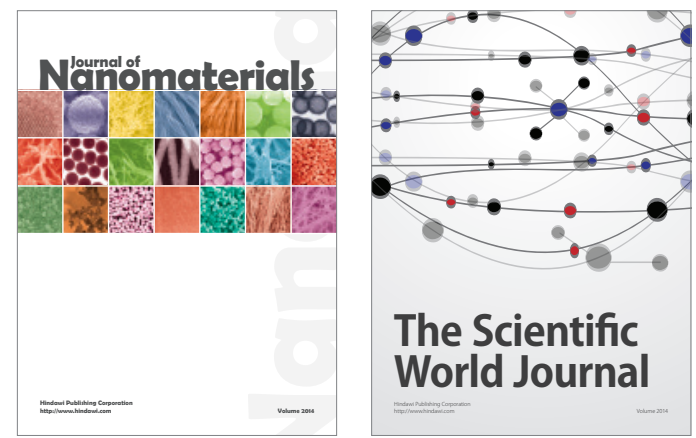

The Scientific World Journal
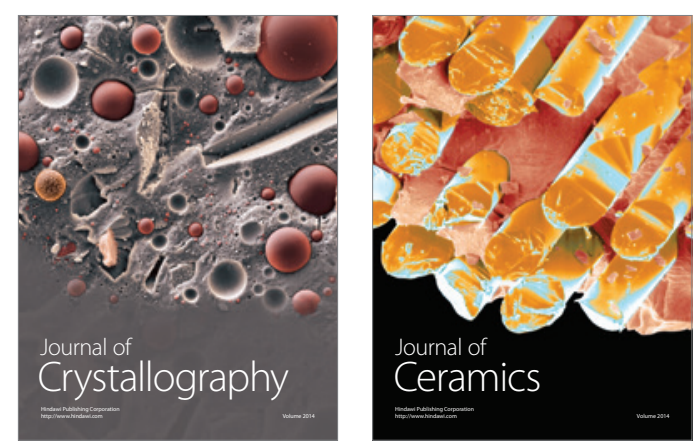
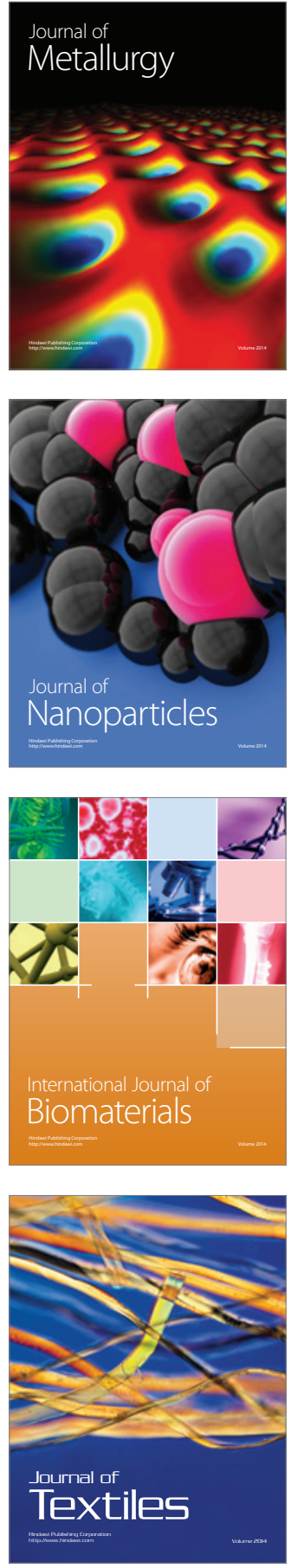